\title{
Variations of the thermal growing season during the period 1961-2015 in northern China
}

\author{
CUI Linli ${ }^{1,2^{*}}$, SHI Jun ${ }^{2,3}$, MA Yue ${ }^{3}$, LIU Xiaochen ${ }^{2,3}$ \\ ${ }^{1}$ Shanghai Institute of Meteorological Science, Shanghai Meteorological Bureau, Shanghai 200030, China; \\ ${ }^{2}$ Shanghai Key Laboratory of Meteorology and Health, Shanghai 200030, China; \\ ${ }^{3}$ Shanghai Climate Center, Shanghai Meteorological Bureau, Shanghai 200030, China
}

\begin{abstract}
Researching into changes in thermal growing season has been one of the most important scientific issues in studies of the impact of global climate change on terrestrial ecosystems. However, few studies investigated the differences under various definitions of thermal growing season and compared the trends of thermal growing season in different parts of China. Based on the daily mean air temperatures collected from 877 meteorological stations over northern China from 1961 to 2015, we investigated the variations of the thermal growing season parameters including the onset, ending and duration of the growing season using the methods of differential analysis, trend analysis, comparative analysis, and Kriging interpolation technique. Results indicate that the differences of the maximum values of those indices for the thermal growing season were significant, while they were insignificant for the mean values. For indices with the same length of the spells exceeding $5^{\circ} \mathrm{C}$, frost criterion had a significant effect on the differences of the maximum values. The differences of the mean values between frost and non-frost indices were also slight, even smaller than those from the different lengths of the spells. Temporally, the starting date of the thermal growing season advanced by 10.0-11.0 days, while the ending dates delayed by 5.0-6.0 days during the period 1961-2015. Consequently, the duration of the thermal growing season was prolonged 15.0-16.0 days. Spatially, the advanced onset of the thermal growing season occurred in the southwestern, eastern, and northeastern parts of northern China, whereas the delayed ending of the thermal growing season appeared in the western part, and the length of the thermal growing season was prolonged significantly in the vast majority of northern China. The trend values of the thermal growing season were affected by altitude. The magnitude of the earlier onset of the thermal growing season decreased, and that of the later ending increased rapidly as the altitude increased, causing the magnitude of the prolonged growing season increased correspondingly. Comparing the applicability of selected indices and considering the impacts of frost on the definitions are important and necessary for determining the timing and length of the thermal growing season in northern China.
\end{abstract}

Keywords: daily mean air temperatures; length of the growing season; starting date of the thermal growing season; ending date of the thermal growing season; trend; northern China

Citation: CUI Linli, SHI Jun, MA Yue, LIU Xiaochen. 2018. Variations of the thermal growing season during the period 1961-2015 in northern China. Journal of Arid Land, 10(2): 264-276. https://doi.org/10.1007/s40333-018-0001-6

\section{Introduction}

The global-mean surface temperature records show a linear warming trend of $0.85^{\circ} \mathrm{C}$ during the period 1880-2012, and this increase in surface temperature is projected to likely be $0.3^{\circ} \mathrm{C}-4.8^{\circ} \mathrm{C}$

\footnotetext{
*Corresponding author: CUI Linli (E-mail: cllcontact@163.com)

Received 2017-02-20; revised 2017-11-28; accepted 2017-12-07

(C) Xinjiang Institute of Ecology and Geography, Chinese Academy of Sciences, Science Press and Springer-Verlag GmbH Germany, part of Springer Nature 2018
} 
globally for 2081-2100 relative to 1986-2005 (IPCC, 2013). Global warming has shifted the timing of seasons with earlier spring, later autumn and earlier peak photosynthesis (Burrows et al., 2011; Barichivich et al., 2012; $\mathrm{Xu}$ et al., 2016), and has extended the length of growing season (Piao et al., 2007; Wang et al., 2016). Changes in the vegetation growing season could not only affect the structure and function of ecosystems, but also lead to variations of agricultural production and carbon sequestration potential, which in turn may affect global and regional climate (Linderholm, 2006; Piao et al., 2007; Mozafari and Torki, 2015; Wang et al., 2016). Therefore, researching into the change of vegetation growing season has been one of the most important scientific issues in the studies of global climate change and terrestrial ecosystems (Mozafari and Torki, 2015; Yang et al., 2016).

Thermal growing season is a period of time when plant growth can occur in theory, in other words, the constraints of temperature on plant growth are cancelled and growth will take place if other environmental needs are met (Carter, 1998). It is generally expressed as the number of days when air temperatures are higher than a predefined threshold (Shen et al., 2012; Guo et al., 2016). For example, Carter (1998) defined the start of growing season as daily mean temperature $\geq 5^{\circ} \mathrm{C}$ for $>5$ days and the end as the 10-day running mean when daily temperature $<5^{\circ} \mathrm{C}$. Dong et al. (2012) considered the thermal growing season as the period beginning on the last day of the first 6-day spell with daily mean temperature $\geq 5^{\circ} \mathrm{C}$ after the last spring frost and the end on the first day of the first 10 -day spell with mean temperature $<5^{\circ} \mathrm{C}$. Guo et al. (2016) took the start of growing season as the last day of the first 5-day spell with daily mean temperature $\geq 5^{\circ} \mathrm{C}$, and the end as the last day of the first 5-day spell with mean temperature $<5^{\circ} \mathrm{C}$.

Under the background of climate change, the changes in the mean temperature are anticipated to be mirrored in the changes of the growing season. However, the relationships between climate and thermal growing season are regionally different, and there is no universal method which is widely applicable to all regions to define the thermal growing season (Linderholm, 2006). Moreover, the indices of thermal growing season reflect the climate change in different ways, and even a small change in the indices definition may lead to distinctly heterogeneous results in the same regions. Although several scholars have analyzed the thermal growing season in the whole China or regions of China (Song et al., 2010; Dong et al., 2012; Yang et al., 2013; Guo et al., 2016), few studies have conducted an in-depth comparison of the changes of the growing season in different parts of China with various definitions of indices (Song et al., 2010). Thus, the objectives of this study are to compare the different definitions of thermal growing season parameters (starting date, ending date, and the length of the thermal growing season) and to analyze their variations and trends in northern China, based on daily mean air temperature data from 877 stations during the period 1961-2015.

\section{Materials and methods}

\subsection{Study area}

Northern China lies in the mid-latitudes of the Northern Hemisphere. This study was conducted in the regions north of the $33^{\circ} \mathrm{N}$, including Xinjiang, Inner Mongolia, Heilongjiang, Jilin, Liaoning, Hebei, Beijing, Tianjin, Shandong, Shanxi, Ningxia, most of Henan, Shaanxi, Gansu and Qinghai, and some northern parts of Jiangsu, Anhui and Tibet (Fig. 1a). Strongly influenced by the East Asian monsoon, the study area is mostly characterized by arid and semi-arid climates, with the rainy season occurring in summer (June-August). Generally, the annual mean temperature ranges from $-4^{\circ} \mathrm{C}$ to $14^{\circ} \mathrm{C}$, and the annual precipitation varies from 25 to $1000 \mathrm{~mm}$. There is a variety of complex topography, including mountains, basins, plateaus, hills and plains, and the regional landscape consists of various biomes, such as grasslands, farmlands, forests, deserts, shrubs and so on (Sun et al., 2015). 


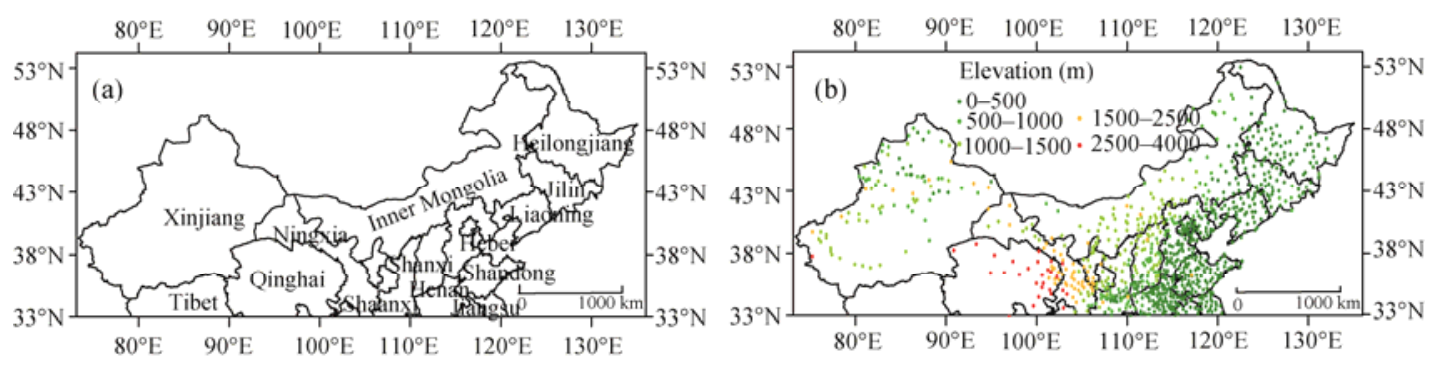

Fig. 1 Administrative division (a) and spatial distribution of selected meteorological stations (b) in northern China

\subsection{Data collection}

Daily mean air temperature data were used to calculate the growing season parameters (starting date, ending date, and the length of the growing season). These data came from the National Meteorological Information Center, China Meteorological Administration with the time span 1951-2015. Totally, there were 1218 surface weather observation stations available in northern China. Given the higher missing rate of the original data and the less number of stations before 1961, we only used those observation data obtained during the period 1961-2015. Meanwhile, stations with average missing rates of over 1\% were also excluded from our studies. Finally, 877 out of 1218 meteorological stations were used, which had an average missing rate of less than $1 \%$ during the whole year and in spring and autumn over the past 55 years. The spatial distribution of selected stations was shown in Figure 1b. The missing data from a single day was filled in by the average of its adjacent days before and after, and the missing values of two or more than two consecutive days were filled with the simple linear regression method according to the observation data of neighboring stations which had the highest correlation coefficient with the former data and had no missing data during the same period.

\subsection{Methods}

We calculated a set of growing season indices, including the starting date of the growing season (SI), the ending date of the growing season (EI), and the length of the growing season (LI), from daily mean temperature data based on different criteria as Table 1. In this study, four indices were used to determine the starting date and another five indices were used to determine the ending date of the growing season. Starting and ending indices were then combined to six different indices for the length of the growing season. Since the threshold of $5^{\circ} \mathrm{C}$ daily mean temperature has been widely accepted for determining the thermal growing season (Carter, 1998, Frich et al., 2002, Jones et al., 2002; Walther and Linderholm, 2006; Song et al., 2010; Dong et al., 2012; Guo et al., 2016), here we also used it in all of the indices. The main differences between indices were presented in the lengths of the spells when daily mean temperature was over $5^{\circ} \mathrm{C}$ (starting date) or below $5^{\circ} \mathrm{C}$ (ending date). All indices that were used are listed in Table 1 .

In order to evaluate the strength of the relationship between indices, we compared the differences in both the mean and the maximum values for different combinations of indices. The difference between indices was firstly counted year-by-year at each station. Then, based on the 55-year data sequence, we calculated the long-term average as the mean value at each station, and the maximum value at each station was simultaneously selected from the 55-year data sequence. Finally, the regional mean value was calculated using the station-averaged method and the regional maximum value was directly selected from the 877 stations and each combination had only one maximum value.

The linear trends of time-series indices were also investigated. According to the latitude and longitude of stations, the Kriging interpolation technique was applied to generate the spatial patterns of the difference and trend for the thermal growing season, and the results were displayed by Golden Software Surfer. Given the sparse meteorological stations in some parts of northeastern China and most parts of western China, the interpolation results in these areas may not be able to correctly reflect the real variations to some extent. 
Table 1 Definition of the indices of starting date, ending date and length of the thermal growing season in this study

\begin{tabular}{|c|c|c|}
\hline Parameter & Index & Definition \\
\hline \multirow{4}{*}{$\begin{array}{l}\text { Starting } \\
\text { date of the } \\
\text { growing } \\
\text { season } \\
\text { (SI) }\end{array}$} & $=5 \mathrm{~d}>5^{\circ} \mathrm{C}(\mathrm{SI} 1)$ & 5-day spell with $\mathrm{T}_{\text {mean }}$ remaining above $5^{\circ} \mathrm{C}$ \\
\hline & $>5 \mathrm{~d}>5^{\circ} \mathrm{C}$ (SI 2$)$ & 6-day spell with $\mathrm{T}_{\text {mean }}$ remaining above $5^{\circ} \mathrm{C}$ \\
\hline & & $\begin{array}{l}\text { 5-day spell after the last } \mathrm{T}_{\text {mean }} \text { spring frost with } \mathrm{T}_{\text {mean }} \text { remaining } \\
\text { above } 5^{\circ} \mathrm{C}\end{array}$ \\
\hline & $>5 \mathrm{~d}>5^{\circ} \mathrm{C} \mathrm{Fr}(\mathrm{SI} 4)$ & $\begin{array}{l}\text { 6-day spell after the last } \mathrm{T}_{\text {mean }} \text { spring frost with } \mathrm{T}_{\text {mean }} \text { remaining } \\
\text { above } 5^{\circ} \mathrm{C}\end{array}$ \\
\hline \multirow{5}{*}{$\begin{array}{l}\text { Ending } \\
\text { date of the } \\
\text { growing } \\
\text { season } \\
\text { (EI) }\end{array}$} & $=5 \mathrm{~d}<5^{\circ} \mathrm{C}(\mathrm{EI} 1)$ & 5-day spell with $\mathrm{T}_{\text {mean }}$ remaining below $5^{\circ} \mathrm{C}$ \\
\hline & $>5 \mathrm{~d}<5^{\circ} \mathrm{C}(\mathrm{EI} 2)$ & 6-day spell with $\mathrm{T}_{\text {mean }}$ remaining below $5^{\circ} \mathrm{C}$ \\
\hline & $=10 \mathrm{~d}<5^{\circ} \mathrm{C}(\mathrm{EI} 3)$ & 10-day running mean of $\mathrm{T}_{\text {mean }}$ falling below $5^{\circ} \mathrm{C}$ \\
\hline & Fr or $=5 \mathrm{~d}<5^{\circ} \mathrm{C}(\mathrm{EI} 4)$ & $\begin{array}{l}\text { First autumn/winter } T_{\text {mean }} \text {-frost or 5-day spell with } T_{\text {mean }} \\
\text { remaining below } 5^{\circ} \mathrm{C}\end{array}$ \\
\hline & Fr or $>5 \mathrm{~d}<5^{\circ} \mathrm{C}($ EI 5$)$ & $\begin{array}{l}\text { First autumn/winter } T_{\text {mean }} \text {-frost or } 6 \text {-day spell with } T_{\text {mean }} \\
\text { remaining below } 5^{\circ} \mathrm{C}\end{array}$ \\
\hline \multirow{6}{*}{$\begin{array}{l}\text { Length of } \\
\text { the } \\
\text { growing } \\
\text { season } \\
\text { (LI) }\end{array}$} & $=5 \mathrm{~d}>5^{\circ} \mathrm{C} \mid=5 \mathrm{~d}<5^{\circ} \mathrm{C}($ LI 1$)$ & Start (SI 1), End (EI 1) \\
\hline & $>5 \mathrm{~d}>5^{\circ} \mathrm{C} \mid>5 \mathrm{~d}<5^{\circ} \mathrm{C}($ LI 2$)$ & Start (SI 2), End (EI 2) \\
\hline & $=5 \mathrm{~d}>5^{\circ} \mathrm{C} \mathrm{Fr} \mid=10 \mathrm{~d}<5^{\circ} \mathrm{C}(\mathrm{LI} 3)$ & Start (SI 3), End (EI 3) \\
\hline & $>5 \mathrm{~d}>5^{\circ} \mathrm{C} \mathrm{Fr} \mid=10 \mathrm{~d}<5^{\circ} \mathrm{C}(\mathrm{LI} 4)$ & Start (SI 4), End (EI 3) \\
\hline & $=5 \mathrm{~d}>5^{\circ} \mathrm{C} \mathrm{Fr} \mid \mathrm{Fr}$ or $=5 \mathrm{~d}<5^{\circ} \mathrm{C}(\mathrm{LI} 5)$ & Start (SI 3), End (EI 4) \\
\hline & $>5 \mathrm{~d}>5^{\circ} \mathrm{C}$ Fr $\mid$ Fr or $>5 \mathrm{~d}<5^{\circ} \mathrm{C}($ LI 6$)$ & Start (SI 4), End (EI 5) \\
\hline
\end{tabular}

Note: $\mathrm{T}_{\text {mean }}$, mean air temperature; Fr, frost.

\section{Results}

\subsection{Differences for combinations of growing season indices}

\subsubsection{Starting date of the growing season}

Time series of the mean starting date of the growing season are displayed in Figure 2. SI 1 $\left(=5 \mathrm{~d}>5^{\circ} \mathrm{C}\right)$ had the earliest start, while SI $4\left(>5 \mathrm{~d}>5^{\circ} \mathrm{C} \mathrm{Fr}\right)$ had the latest start of the growing season, with the difference of 4.4 days in the mean values during the period 1961-2015 (Table 2). Meanwhile, SI 1 had an earlier start of 3.2 days than SI $2\left(>5 \mathrm{~d}>5^{\circ} \mathrm{C}\right)$. Two indices including the frost criteria, i.e., SI $3\left(=5 \mathrm{~d}>5^{\circ} \mathrm{C} \mathrm{Fr}\right)$ and SI 4 had later start of the growing season than those not including the frost criteria (SI 1 and SI 2), with the differences of 1.8 and 1.2 days, respectively (Fig. 2). Therefore, the differences in the mean values between a frost index and a non-frost index are relatively little. Including the frost criterion or not in the definition can provide smaller differences than those from the different lengths of the spells exceeding $5^{\circ} \mathrm{C}$.

At 877 stations in northern China, the largest difference of the mean values for the starting date of the growing season was 12.4 days (Table 2) at Wushaoling station (3045 m a.s.1.) in Gansu. For the differences of the maximum values, the regional averages ranged from 17.5 to 28.5 days, and the maximum value were 64.0 days in pairs of SI 2-SI 1 and SI 4-SI 1, both occurred at Sheyang station in Jiangsu. For all the six combinations of the indices, the regional averaged difference was 2.2 days for the mean values, and 22.1 days for the maximum values over the past 55 years. Thus, the low difference in the mean values can only reflect the range of values to some extent, and the difference in the maximum values between indices was large.

3.1.2 Ending date of the growing season

For the five ending indices of the growing season, EI $3\left(10 \mathrm{~d}<5^{\circ} \mathrm{C}\right)$ had the earliest end, and EI 2 $\left(>5 \mathrm{~d}<5^{\circ} \mathrm{C}\right)$ had the latest end of the growing season, with the difference of 9.4 days for the mean 

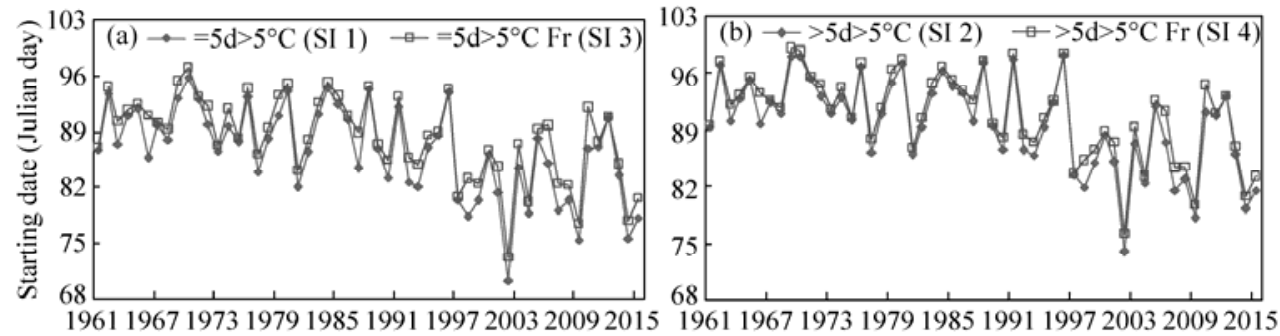

Fig. 2 Effects of consecutive days and frost (Fr) criterion on the starting date of the growing season during the period 1961-2015 in northern China

Table 2 Differences of the mean and maximum values for combinations of starting indices at stations in northern China

\begin{tabular}{cccccc}
\hline \multirow{2}{*}{ Combinations } & \multicolumn{2}{c}{ Differences of the mean values (days) } & & \multicolumn{2}{c}{ Differences of the maximum values (days) } \\
\cline { 2 - 3 } \cline { 5 - 5 } & Mean & Maximum & Mean & 26.3 & 64 \\
\hline SI 2-SI 1 & 3.2 & 1.9 & 21.1 & 58 \\
SI 3-SI 1 & 1.8 & 10.0 & 28.5 & 64 \\
SI 4-SI 1 & 4.4 & 12.4 & $21.6(-17.5)$ & $53(-57)$ \\
SI 2-SI 3 & 1.4 & 7.2 & 17.5 & 57 \\
SI 4-SI 2 & 1.2 & 8.4 & 21.6 & 53 \\
SI 4-SI 3 & 2.6 & 7.2 &
\end{tabular}

Note: For the mean differences, the positive and the negative values are counted together; and for the maximum differences, they are counted separately. The negative values in parentheses represent the former index is less than the latter index at some stations or in some years. The description of the difference is the same as in Tables 3 and 4.

values during the period 1961-2015 (Table 3). Meanwhile, EI 2 had a later end of 1.8 days than EI $1\left(=5 \mathrm{~d}<5^{\circ} \mathrm{C}\right)$, and EI 1 had a later end of 7.6 days than EI 3 averagely. The difference between EI 4 (Fr or $=5 \mathrm{~d}<5^{\circ} \mathrm{C}$ ) and EI 5 (Fr or $>5 \mathrm{~d}<5^{\circ} \mathrm{C}$ ) was relatively low (1.1 days). Two indices including the frost criteria, i.e., EI 5 and EI 4 had earlier end of the growing season than EI 2 and EI 1, with the differences of 1.3 and 2.0 days for the mean values, respectively (Fig. 3). Therefore, indices including the frost criterion or not can also cause smaller differences than those from the different lengths of the spells in the definition of the ending date of the growing season.

In northern China, the largest difference of the mean values for the ending date of the growing season was 14.1 days, at Hua Shan Mountain station in Shaanxi for the pair of EI 2 vs. EI 3 during the period 1961-2015 (Table 3). For the differences of the maximum values, the regional averages ranged from 7.9 to 29.9 days, and the maximum value was 54.0 days occurred at Suiping station in Henan. For all the ten combinations of the indices, the regional averaged difference was 4.0 days for the mean values and 23.0 days for the maximum values, respectively, while for the six combinations excluding EI 3, the regional averaged differences for the mean and maximum values were 1.6 and 20.7 days. Thus, the difference among indices was in general small for the mean values, especially when EI 3 index was excluded, but that for the maximum values was still large.

\subsubsection{Length of the growing season}

For the six indices of the length of the growing season, LI $4\left(>5 \mathrm{~d}>5^{\circ} \mathrm{C} \mathrm{Fr} \mid 10 \mathrm{~d}<5^{\circ} \mathrm{C}\right)$ had the shortest length, and LI $1\left(=5 \mathrm{~d}>5^{\circ} \mathrm{C} \mid=5 \mathrm{~d}<5^{\circ} \mathrm{C}\right)$ had the longest length of the growing season, with the difference of 12.0 days for the mean values (Table 4). Meanwhile, LI 1 had a longer growing season of 9.3 days than LI $3\left(=5 \mathrm{~d}>5^{\circ} \mathrm{C}\right.$ Fr $\left.\mid 10 \mathrm{~d}<5^{\circ} \mathrm{C}\right)$, and LI $2\left(>5 \mathrm{~d}>5^{\circ} \mathrm{C} \mid>5 \mathrm{~d}<5^{\circ} \mathrm{C}\right)$ had a longer growing season of 10.5 days than LI 4 over the past 55 years. The difference for the pair of LI 1 vs. LI 2 was the least (1.4 days). Two indices, including the frost criteria, LI $5\left(=5 \mathrm{~d}>5^{\circ} \mathrm{C} \mathrm{Fr}\right.$ Fr or $\left.=5 \mathrm{~d}<5^{\circ} \mathrm{C}\right)$ and LI $6\left(>5 \mathrm{~d}>5^{\circ} \mathrm{C} \mathrm{Fr} \mid \mathrm{Fr}\right.$ or $\left.>5 \mathrm{~d}<5^{\circ} \mathrm{C}\right)$, had shorter length of the growing season 
than those not including the frost criteria (LI 1 and LI 2), with the differences of 3.1 and 3.2 days, respectively (Fig. 3). Once again it showed that including the frost criterion or not could cause smaller differences of the mean values than those from the different lengths of the spells in the definition of the length of the growing season.

Table 3 Differences of the mean and maximum values for combinations of ending indices at stations in northern China

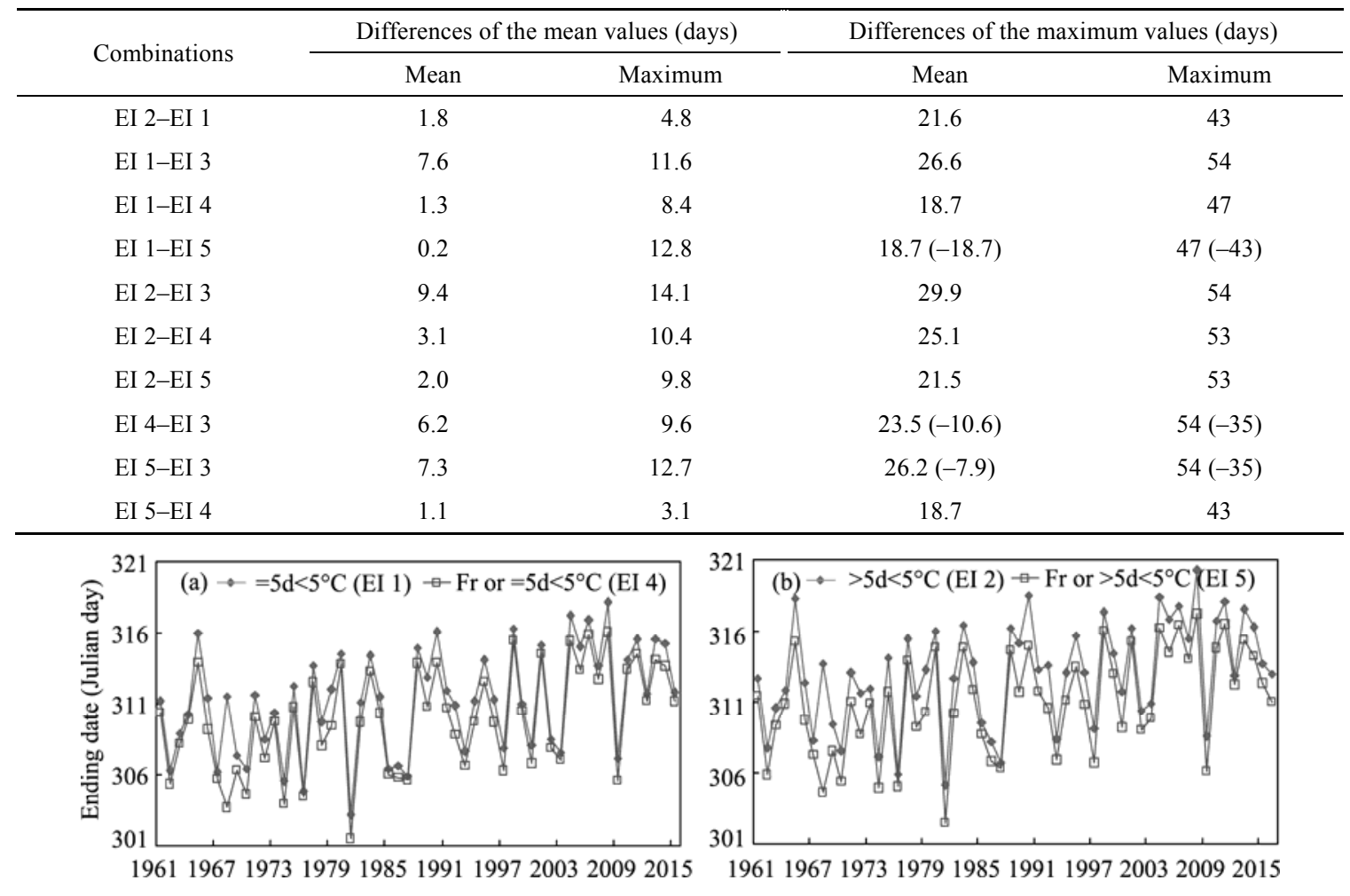

Fig. 3 Effects of consecutive days and frost (Fr) criterion on the ending date of the growing season during the period 1961-2015 in northern China

At 877 stations in northern China, the largest difference of the growing season's length for the mean values was 22.5 days at Wushaoling station in Gansu during 1961-2015, which occurred in the pair of LI 1 vs. LI 4 (Table 4). For the differences of the maximum values, the regional averages were ranged from 3.3 to 39.2 days, and the maximum value was 93.0 days occurred at Xifeng station (1421 m a.s.1.) in Gansu. For the whole study area, the regional averaged difference was 5.7 days for the mean values and 28.6 days for the maximum values, if all fifteen combinations were considered. Thus, although the average difference of the mean values was small, the difference in the maximum values was also large.
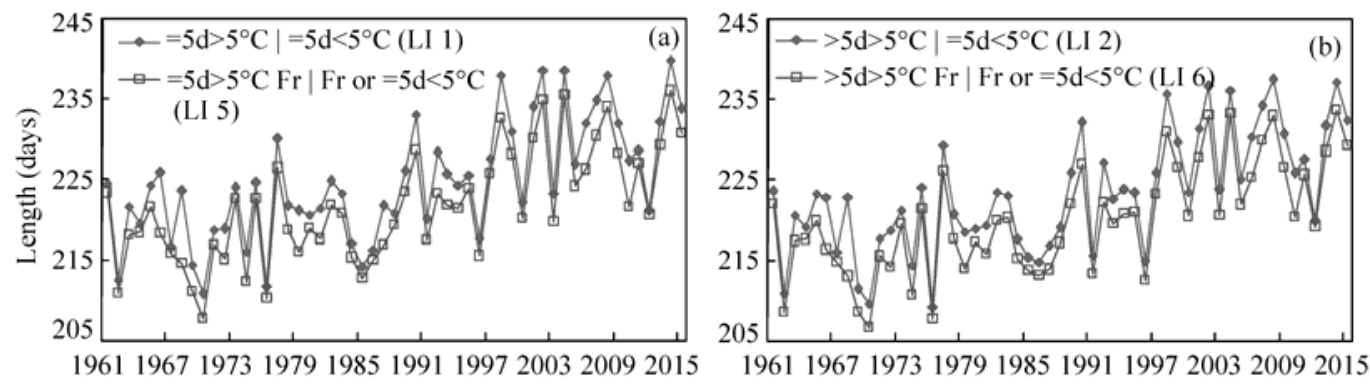

Fig. 4 Effects of consecutive days and frost (Fr) criterion on the length of the growing season during the period 1961-2015 in northern China 
Table 4 Differences of the mean and maximum values for combinations of length indices at stations in northern China

\begin{tabular}{|c|c|c|c|c|}
\hline \multirow{2}{*}{ Combinations } & \multicolumn{2}{|c|}{ Differences of the mean values (days) } & \multicolumn{2}{|c|}{ Differences of the maximum values (days) } \\
\hline & Mean & Maximum & Mean & Maximum \\
\hline LI 1-LI 2 & 1.4 & 5.5 & $25.5(-19.8)$ & $64(-42)$ \\
\hline LI 1-LI 3 & 9.3 & 17.5 & 33.4 & 78 \\
\hline LI 1-LI 4 & 12.0 & 22.5 & $39.2(-3.3)$ & $85(-32)$ \\
\hline LI 1-LI 5 & 3.1 & 14.3 & 26.7 & 73 \\
\hline LI 1-LI 6 & 4.6 & 21.6 & $31.9(-16.2)$ & $73(-42)$ \\
\hline LI 2-LI 3 & 7.9 & 21.0 & $33.7(-15.1)$ & $93(-45)$ \\
\hline LI 2-LI 4 & 10.5 & 17.0 & 34.7 & 93 \\
\hline LI 2-LI 5 & 1.7 & 17.9 & $28.5(-20.5)$ & $69(-53)$ \\
\hline LI 2-LI 6 & 3.2 & 12.9 & 26.8 & 66 \\
\hline LI 3-LI 4 & 2.6 & 7.2 & 21.6 & 53 \\
\hline LI 5-LI 3 & 6.2 & 9.6 & $23.5(-10.6)$ & $54(-35)$ \\
\hline LI 6-LI 3 & 4.7 & 9.0 & $24.5(-18.2)$ & $53(-44)$ \\
\hline LI 5-LI 4 & 8.9 & 14.6 & $31.4(-8.8)$ & $71(-35)$ \\
\hline LI 6-LI 4 & 7.3 & 12.7 & $26.2(-7.9)$ & $54(-35)$ \\
\hline LI 5-LI 6 & 1.5 & 4.5 & $21.2(-17.0)$ & $53(-42)$ \\
\hline
\end{tabular}

\subsection{Spatial and temporal trends for growing season indices}

\subsubsection{Starting date of the growing season}

Except for several scattered stations in western China, earlier onset of the growing season occurred at all stations, regardless of the indices selected. The difference of trends among four indices was relatively small, so the trend values were little affected by the method chosen (Fig. 5). For the four indices of the growing season, the starting date advanced significantly at rates of 1.0-5.5 days per decade in the southwestern, eastern and northeastern parts of the study area, including western Qinghai, most of Inner Mongolia and Shaanxi, north-central Heilongjiang, western Jilin, southern Liaoning, southern Hebei, Shandong, northeastern Henan, northern Anhui, northern Jiangsu, western Shanxi, Ningxia, southeastern and north-central Gansu, and some areas in Xinjiang and Tibet, of which areas with earlier onset of the growing season by 1.0-3.7 days per decade accounted for the largest proportion.
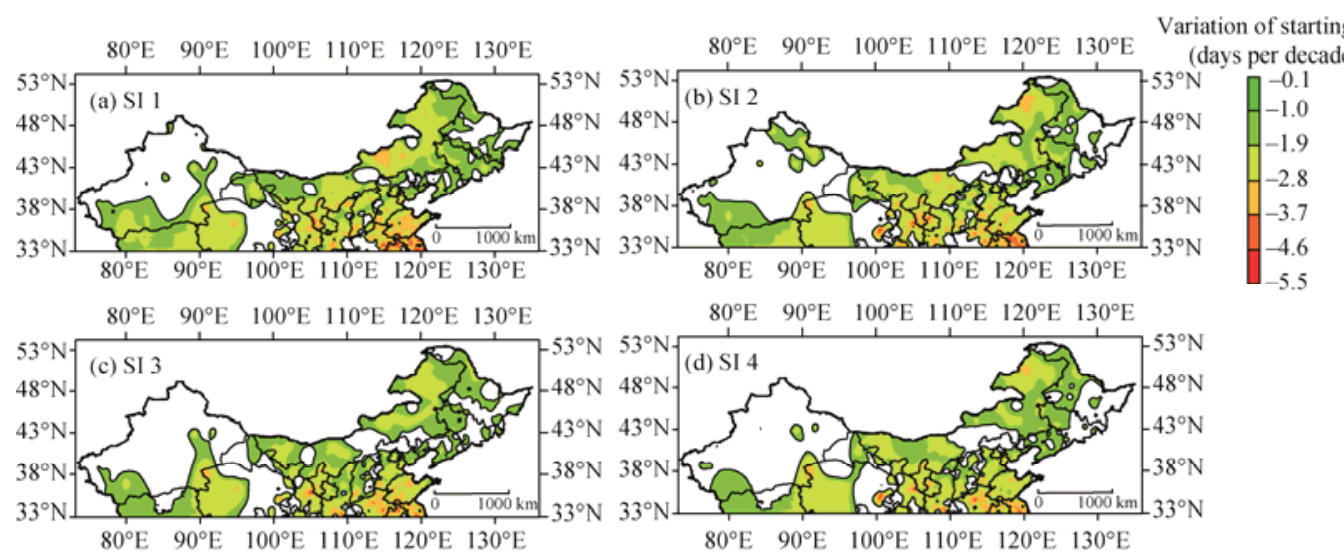

Fig. 5 Linear trends (days per decade) in the starting indices of the growing season during the period 1961-2015 in northern China. Areas of significant changes $(P<0.05)$ were colored while those with insignificant changes $(P>0.05)$ were not colored and shown as white spaces. The description is the same as in Figures 6 and 7. 
For all 877 stations, the averaged changes in four starting indices of the growing season ranged from -11.3 to -10.1 days during 1961-2015 (Table 5). Statistics showed that there were 608, 602, 586 and 576 stations with significant advancing rates of 1.0-5.5 days per decade for SI 1, SI 2, SI 3 and SI 4 , accounting for $69.3 \%, 68.6 \%, 66.8 \%$ and $65.7 \%$ of the total stations across northern China, respectively, of which there were $54.4 \%, 56.0 \%, 56.6 \%$ and $56.3 \%$ of stations with significant advancing rates of 1.0-3.0 days per decade, respectively. Areas with significant advance of the growing season reduced gradually from SI 1 to SI 4 (Fig. 5). None of station had significant later onset of the growing season for all four indices. Indices including the frost criteria brought about changes of 1.0 day less than those disregarding frost criteria on average.

Table 5 Changes in the regional averaged growing season indices during the period 1961-2015 in northern China

\begin{tabular}{|c|c|c|c|c|c|}
\hline \multirow{2}{*}{ Parameter } & \multirow{2}{*}{ Index } & \multirow{2}{*}{$\begin{array}{c}\text { Average } \\
\text { change } \\
\text { (days) }\end{array}$} & \multicolumn{3}{|c|}{ Change with altitude (days) } \\
\hline & & & $0-1000 \mathrm{~m}$ & $1000-2500 \mathrm{~m}$ & $2500-4000 \mathrm{~m}$ \\
\hline \multirow{4}{*}{$\begin{array}{l}\text { Starting date of the } \\
\text { growing season }\end{array}$} & $=5 \mathrm{~d}>5^{\circ} \mathrm{C}(\mathrm{SI} 1)$ & -11.3 & -11.5 & -10.9 & -8.6 \\
\hline & $>5 \mathrm{~d}>5^{\circ} \mathrm{C}$ (SI 2) & -11.0 & -11.2 & -10.6 & -8.4 \\
\hline & $=5 \mathrm{~d}>5^{\circ} \mathrm{C}$ Fr $($ SI 3$)$ & -10.2 & -10.8 & -8.9 & -7.7 \\
\hline & $>5 \mathrm{~d}>5^{\circ} \mathrm{C}$ Fr $(\mathrm{SI} 4)$ & -10.1 & -10.6 & -8.8 & -7.9 \\
\hline \multirow{5}{*}{$\begin{array}{l}\text { Ending date of the } \\
\text { growing season }\end{array}$} & $=5 \mathrm{~d}<5^{\circ} \mathrm{C}(\mathrm{EI} 1)$ & 5.1 & 4.5 & 6.3 & 10.2 \\
\hline & $>5 \mathrm{~d}<5^{\circ} \mathrm{C}($ EI 2$)$ & 5.3 & 4.7 & 6.6 & 9.6 \\
\hline & $=10 \mathrm{~d}<5^{\circ} \mathrm{C}(\mathrm{EI} 3)$ & 5.6 & 4.8 & 7.1 & 10.1 \\
\hline & Fr or $=5 d<5^{\circ} \mathrm{C}(\mathrm{EI} 4)$ & 5.7 & 4.9 & 7.0 & 12.6 \\
\hline & Fr or $>5 \mathrm{~d}<5^{\circ} \mathrm{C}(\mathrm{EI} 5)$ & 5.9 & 5.1 & 7.4 & 12.1 \\
\hline \multirow{6}{*}{$\begin{array}{l}\text { Length of the } \\
\text { growing season }\end{array}$} & $=5 \mathrm{~d}>5^{\circ} \mathrm{C} \mid=5 \mathrm{~d}<5^{\circ} \mathrm{C}($ LI 1$)$ & 16.4 & 16.0 & 17.2 & 18.8 \\
\hline & $>5 \mathrm{~d}>5^{\circ} \mathrm{C} \mid>5 \mathrm{~d}<5^{\circ} \mathrm{C}($ LI 2$)$ & 16.3 & 15.9 & 17.2 & 18.0 \\
\hline & $=5 \mathrm{~d}>5^{\circ} \mathrm{C} \mathrm{Fr} \mid=10 \mathrm{~d}<5^{\circ} \mathrm{C}(\mathrm{LI} 3)$ & 15.8 & 15.7 & 15.9 & 17.8 \\
\hline & $>5 \mathrm{~d}>5^{\circ} \mathrm{C} \mathrm{Fr} \mid=10 \mathrm{~d}<5^{\circ} \mathrm{C}(\mathrm{LI} 4)$ & 15.7 & 15.5 & 15.9 & 18.0 \\
\hline & $=5 \mathrm{~d}>5^{\circ} \mathrm{C} \mathrm{Fr} \mid$ Fr or $=5 \mathrm{~d}<5^{\circ} \mathrm{C}($ LI 5) & 16.0 & 15.8 & 15.9 & 20.2 \\
\hline & $>5 \mathrm{~d}>5^{\circ} \mathrm{C} \mathrm{Fr} \mid$ Fr or $>5 \mathrm{~d}<5^{\circ} \mathrm{C}($ LI 6$)$ & 16.0 & 15.8 & 16.2 & 20.0 \\
\hline
\end{tabular}

Over the past 55 years, the maximum difference for the change of the starting date of the growing season was 19.0 days at Shangnan station in Shaanxi among four indices used, and Fuping station in Hebei seemed to be the most insensitive to the indices chosen. The earlier starting date of the growing season was less in higher altitude areas than in lower areas for the four indices (Table 5). In areas with altitudes ranged from 0 to $1000 \mathrm{~m}$ a.s.l., the starting date of the growing season had averagely advanced about 10.6-11.5 days, but in areas with altitudes ranged from 2500 to $4000 \mathrm{~m}$ a.s.l., it advanced about 7.7-8.6 days during 1961-2015. At Tongde station (3148 m a.s.1.) in Qinghai and Huining station (1739 m a.s.1.) in Gansu, the earlier onset of the growing season was the most remarkable (more than 27.0 days).

3.2.2 Ending date of the growing season

Later end of the growing season was observed in the vast majority of northern China except for some small areas in southern and western Liaoning, eastern and southern Hebei, eastern Shanxi, western and southern Henan, the north end of northeastern China and two stations (Aral station and Hoxud station) in Xinjiang. The difference of trends among five indices was also small, and the trends were little affected by the indices chosen (Fig. 6). Being different from the earlier onset of the growing season, which was significantly concentrated in the eastern and northeastern parts, the later end of the growing season was significantly concentrated in the western part of the study area. In northern Tibet, most of Xinjiang and Qinghai, Jilin, central and southwestern 
Heilongjiang, and some areas in Inner Mongolia, Gansu, Shaanxi, Shanxi, Shandong and northern Jiangsu, the ending date was delayed significantly at speeds of 0.5-3.8 days per decade during 1961-2015, of which areas with later end of the growing season by 1.0-3.0 days per decade accounted for the largest proportion.

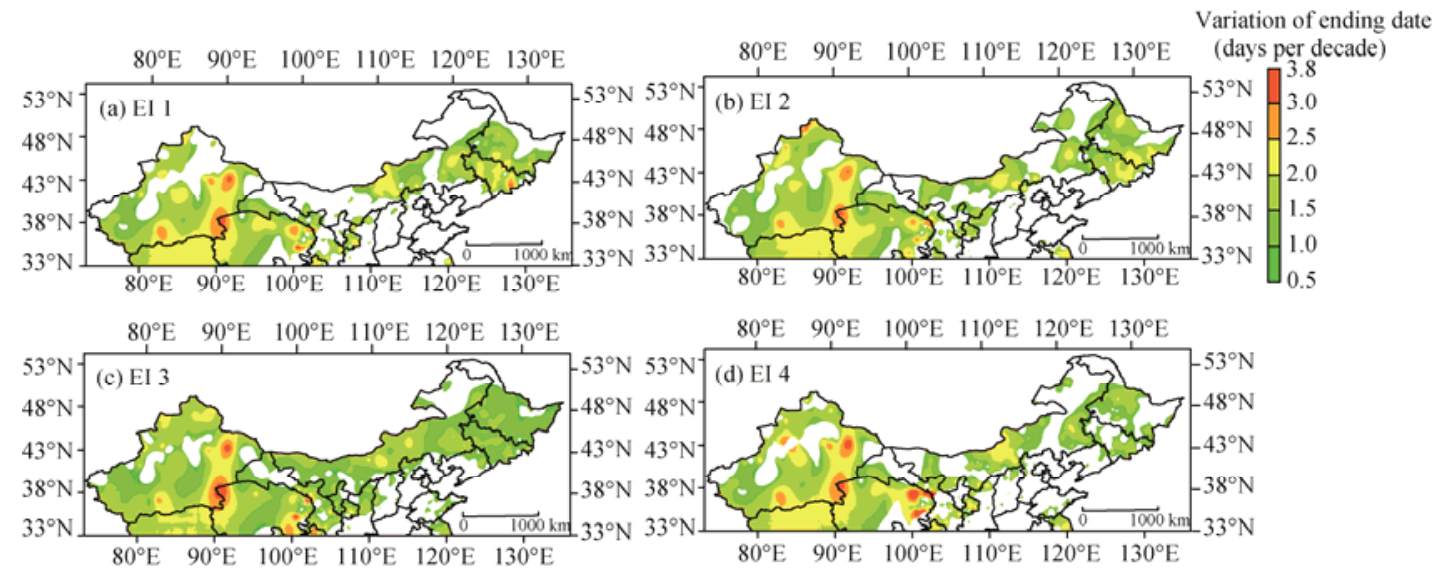

Fig. 6 Linear trends (days per decade) in the ending indices of the growing season during the period 1961-2015 in northern China

Generally, the change of the ending date of the growing season was small. For the five indices, the averaged changes ranged from 5.1 to 5.9 days over northern China during 1961-2015 (Table 5). There were 297, 308, 430, 319 and 331 stations with significant delaying rates of $0.5-3.5$ days per decade for EI 1, EI 2, EI 3, EI 4 and EI 5, accounting for 33.9\%, 35.1\%, 49.0\%, 36.4\% and $37.7 \%$ of the total stations, respectively, of which there were $31.9 \%, 33.5 \%, 46.8 \%, 35.0 \%$ and $36.3 \%$ of stations with significant delaying speeds of 1.0-2.5 days per decade, respectively. For the five indices, EI 3 had the largest areas with significant delay of the growing season, and EI 1 had the smallest areas (Fig. 6). None of station had significant earlier end of the growing season for all five indices. Indices including the frost criteria produced changes of about 0.6 days more than those disregarding frost produced averagely.

During the period 1961-2015, the maximum difference for the change of the ending date of the growing season was 25.9 days at the Wushaoling station among five indices, and Nomhon station (2790 m a.s.1.) in Gansu was the most insensitive to the indices chosen. The ending date of the growing season was delayed more in higher altitude areas than in lower altitude areas for the five indices (Table 5). In areas with altitudes ranged from 0 to $1000 \mathrm{~m}$ a.s.l., the ending date of the growing season had averagely delayed about 4.5-5.1 days, but in areas with altitudes ranged from 2500 to $4000 \mathrm{~m}$ a.s.l., it averagely delayed about 9.6-12.6 days over the past 55 years. At Tongde station and Wushaoling station, the later end of the growing season was the most obvious (more than 20.0 days).

\subsubsection{Length of the growing season}

Except for several stations in Xinjiang, Heilongjiang and Hebei, extended length of the growing season occurred in the whole study area, regardless of the indices selected, and the difference of trends among six indices was also small (Fig. 7). In general, the length of the growing season was significantly extended at rates of 0-9.1 days per decade in the vast majority of northern China during the period 1961-2015, of which areas with prolonged length of the growing season by 1.5-6.0 days per decade accounted for the largest proportion.

The averaged changes for the six indices of the length of the growing season ranged from 15.7 to 16.4 days during the period 1961-2015 (Table 5), and at most of the stations, they were extended from 8.0 to 25.0 days. There were 692, 697, 756, 749, 713 and 712 stations with significant prolonging rates of 0-9.1 days per decade for LI 1, LI 2, LI 3, LI 4, LI 5 and LI 6, accounting for $78.9 \%, 79.5 \%, 86.2 \%, 85.4 \%, 81.3 \%$ and $81.2 \%$ of the total stations across northern China, respectively, of which there were $70.2 \%, 69.4 \%, 80.2 \%, 78.8 \%, 73.3 \%$ and 
$71.2 \%$ of stations with significant prolonging rates of 1.5-4.5 days per decade, respectively. For the six indices, LI 3 had the largest areas with significant extension of the growing season, and LI $1 \mathrm{had}$ the smallest areas. Indices including the frost criteria caused the changes of $0.3-0.4$ days shorter of the length of growing season than those ignoring frost criteria produced averagely.

Over the past 55 years, the maximum difference for the change of the length of growing season was 28.1 days at the Wushaoling station among six indices used, and Dingxin station $(1177 \mathrm{~m}$ a.s.1.) in Gansu was the most insensitive to the indices chosen. The length of the growing season was prolonged more in higher altitude areas than in lower areas for the six indices (Table 5). In areas with altitudes ranged from 0 to $1000 \mathrm{~m}$ a.s.l., the length of the growing season had averagely extended about 15.5-16.0 days, but in areas with altitudes ranged from 2500 to $4000 \mathrm{~m}$ a.s.1., it averagely extended about 17.8-20.2 days during the period 1961-2015. Again at Tongde station and Wushaoling station, the extension of the growing season was the most prominent (more than 40.0 days), and at Aral station (1012 m a.s.1.) in Xinjiang there were small decreases of the length of growing season for all the five indices (not significant).
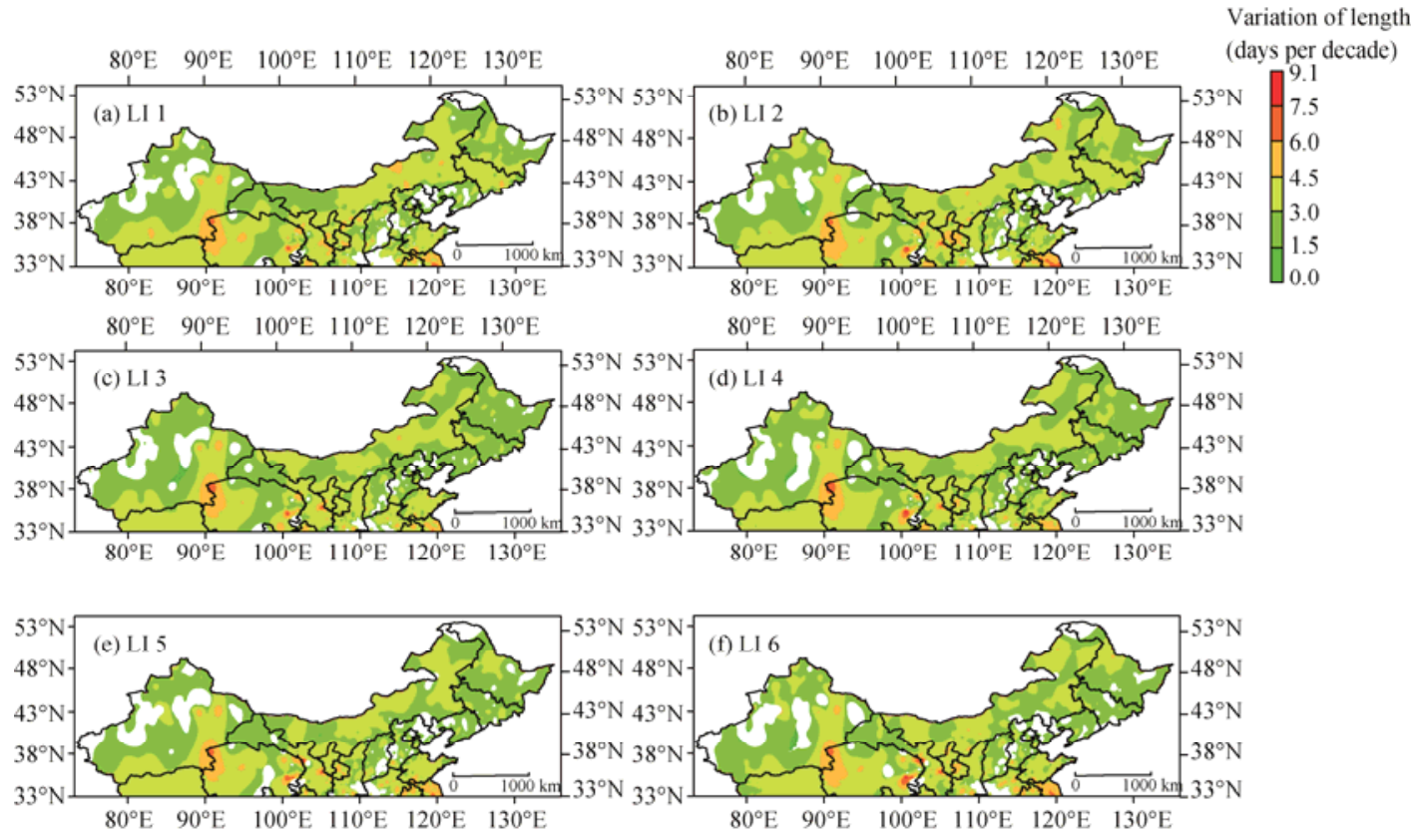

Fig. 7 Linear trends (days per decade) in the length of the growing season during the period 1961-2015 in northern China

\section{Discussion}

The length of growing season is important for local agriculture, carbon sequestration potentials, ecological environment and human activities (Brown et al., 2010). Given that the difference of mean values between a frost index and a non-frost index was relatively small, it had less influence on the statistical analysis of the growing season in northern China (Figs. 2-4) whether including the frost criterion or not. However, the difference of maximum values between a frost index and a non-frost index was large, so in this context the frost criterion had obvious effects on the determination of annual starting date, ending date and the length of the growing season at stations. This is consistent with existing results. For example, Walther and Linderholm (2006) noted that including or excluding the frost criteria had a significant impact on the starting date of the growing season in the south western parts of the Greater Baltic Area, though disregarding the frost criteria during autumn did not have the same importance for the ending date of the growing season. The results from Guo et al. (2013) also showed that frost criterion had a significant influence on the growing season in most central parts of Inner Mongolia, particularly on the onset 
of the growing season.

During the period 1961-2015, the starting date of the growing season had shifted 10.0-11.0 days earlier while the ending date had moved 5.0-6.0 days later, extending the length of the growing season by 15.0-16.0 days in northern China depending on the indices chosen (Table 5). These results are in agreement with others. Song et al. (2010) showed that the thermal growing season had extended at a rate of 2.3 days per decade in northern China during the period 1951-2007. In the Inner Mongolia, China, Guo et al. (2014) also found that the length of the growing season had extended by 22,14,17, and 15 days in the desert, grassland, agriculture, and forest regions during the period 1961-2010, respectively. In temperate China, Shen et al. (2012) found that the starting date of the thermal growing season had shifted 8.4 days earlier though the ending date had moved 5.7 days later from 1960 to 2009 averagely. The results from Guo et al. (2016) also showed that from 1961 to 2013, there were 9.0 and 11.1 days earlier of the onset of tree growing season, and 4.8 and 5.8 days later of the ending date of tree growing season, extending the length of the tree growing season by 13.3 days in the mountainous regions of Hebei and Shanxi and 16.4 days in the Loess Plateau.

In northern China, the impact of different indices from the same category on the long-term trend of the growing season was relatively small, but there were still some differences in different areas and the differences between indices were not homogeneous over the whole area (Figs. 5-7). Walther and Linderholm (2006) compared a lot of definitions of the growing season in the Greater Baltic Area, and also found some differences in trends of the length of growing season depending on the definition used. In addition, the 877 meteorological stations were not evenly distributed, and most of them located in the southeastern part of northern China (Fig. 1). In the southwestern part, including southern Xinjiang, northern Tibet, and southwestern Qinghai, the distribution of stations was sparse. Given that the most widespread land types are deserts, mountains and bare lands in these areas, we calculated the mean and maximum values in this paper using data from the meteorological stations, the relatively small number of stations available in these areas had less impacts on our results, though the interpolation of the results in these areas might have some uncertainties.

Thermal growing season can only estimate the real growing season to a certain extent, and it should be seen as a model approach to determine the growing season using daily mean temperature (Walther and Linderholm, 2006). Phenological data obtained from ground observation can provide real and exact results of growing season parameters because it is the integration of all related environmental factors that promote the growth of plants in a particular area. Zheng et al. (2002) analyzed the changes in the phenology of plants in China based on phenological observation data from 26 stations and found spring phenophases had been advanced in northern China, northeastern China and the lower Yangtze region, but delayed in the middle reaches of Yangtze River and the eastern part of southwestern China since 1980s. Hao et al. (2017) analyzed the phenology data of typical ligneous plants in Kashgar Prefecture and results showed that the phenology of ligneous plants had shift to an earlier date in spring, on average, it had been advanced 8 days gradually during the period 1985-2012. Based on the phenological data of Larix gmelinii during 1987-2012, Yang et al. (2016) found that that growing season of L. gmelinii was prolonged in the Greater Khingan Mountains, especially the first leaf unfolding and the end of leaf fall were delayed by 17.3 and 12.1 days per decade, respectively. However, the availability of phenological data is more limited and only in shorter time scales.

With the development of satellites, remote sensing data can now provide continuous coverage and fine spatial resolution of regional or global vegetation and thus widely used in phenology monitoring (White et al., 2005; Wang et al., 2016). For example, Høgda et al. (2013) analyzed the trends of growing season in Fennoscandia using the Global Inventory Modeling and Mapping Studies NDVI3g data and results showed an earlier start of the growing season of 9.8-13.8 days during the period 1982-2011. Nagai et al. (2015) examined the variations in the timing of the growing season in Japan using daily satellite-observed green-red vegetation index, and found the sensitivity of the ending date of the growing season to air temperature was much less than that of starting date in both deciduous broadleaf and needle leaf forests during the period 2003-2012. 
Chi et al. (2016) showed the heterogeneous trends of the onset of the growing season for different vegetation types in Xilin Gol League, China by using NOAA/AVHRR NDVI data of 1-km resolution during the period 1989-2009. Wang et al. (2016) examined the onset, length, and ending date of the growing season in the Loess Plateau based on NDVI data, and results showed that $54.84 \%$ of the vegetation had an earlier starting date of the growing season, whereas $67.64 \%$ had a later end during the period 2000-2010. Therefore, it is the focus of future research to carefully select the indices and compare the applicability of different indices with a variety of temperature thresholds, combining satellite remote sensing monitoring and plant phenological observation.

\section{Conclusions}

In northern China, the differences of the maximum values among different parameters of the thermal growing season (i.e., starting date, ending date and the length of the growing season) were large, though the differences of the mean values between these indices were small. Therefore, it is necessary to carefully select the indices of the growing season and to compare the applicability of different indices in a variety of geographic and climatic regions. Indices including the frost criterion or not could cause little differences for the mean values, even smaller than those from the different lengths of the spells, but for the maximum values, the differences between frost and non-frost indices were large. Thus the consideration of frost criterion is important for determining the annual timing and the length of growing season in northern China.

Over the past 55 years, the regional average trends of the thermal growing season showed an earlier onset of 10-11 days, a delayed end of 5.0-6.0 days and consequently a prolonged length of 15.0-16.0 days in northern China. Spatially, the starting date of the growing season advanced significantly at rates of 1.0-3.7 days per decade in the southwestern, eastern and northeastern parts of northern China, whereas the ending date delayed significant at rates of 1.0-3.0 days per decade in the western part, and the length of the growing season was prolonged significantly at rates of 1.5-6.0 days per decade in the vast majority of northern China. As the altitude increased, the advancing rate of the growing season decreased, and the delaying rate of the ending date of the growing season increased rapidly, correspondingly, the prolonging rate of the length of the growing season increased.

\section{Acknowledgements}

This work was supported by the National Natural Science Foundation of China $(41571044,41401661,41001283)$, the Climate Change Special Fund of the China Meteorological Administration (CCSF201716) and the China Clean Development Mechanism (CDM) Fund Project (2012043).

\section{References}

Barichivich J, Briffa K R, Osborn T J, et al. 2012. Thermal growing season and timing of biospheric carbon uptake across the northern Hemisphere. Global Biogeochemical Cycles, 26(4): GB4015.

Brown P J, Bradley R S, Keimig F T. 2010. Changes in extreme climate indices for the northeastern United States, 1870-2005. Journal of Climate, 23(24): 6555-6572.

Burrows M T, Schoeman D S, Buckley L B, et al. 2011. The pace of shifting climate in marine and terrestrial ecosystems. Science, 334(6056): 652-655.

Carter T R. 1998. Changes in the thermal growing season in Nordic countries during the past century and prospects for the future. Agricultural and Food Science in Finland, 7(2): 161-179.

Chi D K, Wang H, Li X B, et al. 2016. The variability of growing season of different vegetation types in Xilingol League. Pratacultural Science, 33(9): 1825-1834. (in Chinese)

Dong M Y, Jiang Y, Zheng C T, et al. 2012. Trends in the thermal growing season throughout the Tibetan Plateau during 1960-2009. Agricultural and Forest Meteorology, 166-167: 201-206.

Frich P, Alexander L V, Della-Marta P, et al. 2002. Observed coherent changes in climatic extremes during the second half of the twentieth century. Climate Research, 19(3): 193-212. 
Guo L H, Wu S H, Zhao D S, et al. 2013. Change trends of growing season over Inner Mongolia in the past 50 years. Scientia Geographica Sinica, 33(4): 505-512. (in Chinese)

Guo L H, Wu S H, Zhao D S, et al. 2014. Variations and trends of climatic growing season in different vegetation zones, Inner Mongolia over the past 50 years. Arid Land Geography, 37(3): 532-538. (in Chinese)

Guo Y Y, Jiang Y, Dong M Y, et al. 2016. Trends in the tree growing season throughout the Hebei and Shanxi mountainous region and Loess Plateau of North China from 1961 to 2013. Resources Science, 38(4): 758-767. (in Chinese)

Hao H F, Gu Y Q, Hao H L. 2017. The spring phenological change characteristics of ligneous plants and their response to climate warming in Kashgar prefecture. Journal of Arid Land Resources and Environment, 31(5): 153-157. (in Chinese)

Høgda K A, Tømmervik H, Karlsen S R. 2013. Trends in the start of the growing season in Fennoscandia 1982-2011. Remote Sensing, 5(9): 4304-4318.

IPCC. 2013. Climate Change 2013: The Physical Science Basis. Working Group I Contribution to the Fifth Assessment Report of the Intergovernmental Panel on Climate Change. Cambridge and New York: Cambridge University Press, 1-95.

Jones P D, Briffa K R, Osborn T J, et al. 2002. Relationships between circulation strength and the variability of growing-season and cold-season climate in northern and central Europe. The Holocene, 12(6): 643-656.

Linderholm H W. 2006. Growing season changes in the last century. Agricultural and Forest Meteorology, 137(1-2): 1-14.

Mozafari G, Torki M. 2015. A study of initial, final and growing season length in west of Iran. International Journal of Advanced Biological \& Biomedical Research, 3(1): 65-69.

Nagai S, Saitoh T M, Nasahara K N, et al. 2015. Spatio-temporal distribution of the timing of start and end of growing season along vertical and horizontal gradients in Japan. International Journal of Biometeorology, 59(1): 47-54.

Piao S L, Friedlingstein P, Ciais P, et al. 2007. Growing season extension and its impact on terrestrial carbon cycle in the Northern Hemisphere over the past 2 decades. Global Biogeochemical Cycles, 21(3): GB3018.

Shen M G, Tang Y H, Chen J, et al. 2012. Specification of thermal growing season in temperate China from 1960 to 2009. Climatic Change, 114(3-4): 783-798.

Song Y L, Linderholm H W, Chen D L, et al. 2010. Trends of the thermal growing season in China, 1951-2007. International Journal of Climatology, 30(1): 33-43.

Sun Y L, Yang Y L, Zhang Y, et al. 2015. Assessing vegetation dynamics and their relationships with climatic variability in northern China. Physics and Chemistry of the Earth, Parts A/B/C, 87-88: 79-86.

Walther A, Linderholm H W. 2006. A comparison of growing season indices for the Greater Baltic Area. International Journal of Biometeorology, 51(2): 107-118.

Wang H, Liu G H, Li Z S, et al. 2016. Driving force and changing trends of vegetation phenology in the Loess Plateau of China from 2000 to 2010. Journal of Mountain Science, 13(5): 844-856.

White M A, Hoffman F, Hargrove W, et al. 2005. A global framework for monitoring phenological responses to climate change. Geophysical Research Letters, 32(4): L04705, doi: 10.1029/2004GL021961.

Xu C Y, Liu H Y, Williams A P, et al. 2016. Trends toward an earlier peak of the growing season in northern Hemisphere mid-latitudes. Global Change Biology, 22(8): 2852-2860.

Yang L P, Qin Y, Zhang C H, et al. 2016. Influence of climate change on the phenophase of Larix gmelinii in the Greater Khingan Mountains. Arid Zone Research, 33(3): 577-583. (in Chinese)

Yang X C, Tian Z, Chen B D. 2013. Thermal growing season trends in east China, with emphasis on urbanization effects. International Journal of Climatology, 33(10): 2402-2412.

Zheng J Y, Ge Q S, Hao Z X. 2002. Impacts of climate warming on plants phenophases in China for the last 40 years. Chinese Science Bulletin, 47(21): 1826-1831. 